Bulletin d'Histoire Contemporaine de l'Espagne

$51 \mid 2017$

Les forces politiques durant la Seconde République espagnole

\title{
El Partido Comunista de España en la Segunda República
}

La Parti communiste d'Espagne au cours de la Seconde République

The Communist Party of Spain during the Second Republic

\section{Fernando Hernández Sánchez}

\section{OpenEdition}

\section{Journals}

Edición electrónica

URL: http://journals.openedition.org/bhce/684

DOI: 10.4000/bhce.684

ISSN: 1968-3723

Editor

Presses Universitaires de Provence

Edición impresa

Fecha de publicación: 1 junio 2017

Paginación: 85-100

ISSN: 0987-4135

Referencia electrónica

Fernando Hernández Sánchez, «El Partido Comunista de España en la Segunda República », Bulletin d'Histoire Contemporaine de l'Espagne [En línea], 51 | 2017, Publicado el 09 octubre 2018, consultado el 10 diciembre 2020. URL : http://journals.openedition.org/bhce/684 ; DOI : https://doi.org/10.4000/ bhce.684 


\section{El Partido Comunista de España en la Segunda República}

\section{Fernando HERNÁNDEZ SÁNCHEZ}

Universidad Autónoma, Madrid

$\mathrm{L}$ a Revolución de Octubre de 1917 se convirtió en el tema central del debate sobre la definición de las posiciones del movimiento socialista en la Europa de postguerra. Como sus homólogos continentales, el Partido Socialista Obrero Español (PSOE) se planteó en su congreso de 1919 el estudio de la adhesión a la Internacional Comunista (IC o Komintern) o la permanencia en la socialista. En 1920 sus Juventudes se adelantaron y constituyeron el Partido Comunista (PC). En 1922 se les unieron los simpatizantes probolcheviques del PSOE, que un año antes habían fundado el Partido Comunista Obrero Español (PCOE) tras el rechazo de la mayoría socialista a aceptar las veintiuna condiciones de adhesión impuestas por la Komintern ${ }^{1}$.

\section{Primeros años (1920-1931)}

Los años iniciales del nuevo movimiento estuvieron marcados por el radicalismo ultraizquierdista. Los métodos anarcosindicalistas, considerados como la expresión de lo más genuinamente revolucionario, eran imitados por los jóvenes comunistas que tendían al desencadenamiento de numerosas huelgas inoportunas frustradas en su logro por el planteamiento de objetivos maximalistas y el desarrollo de comportamientos extremadamente violentos ${ }^{2}$. El peso del extremismo y el recurso a la violencia se prolongó durante años y dejó profundas huellas de carácter sectario en la formación de los primeros militantes. Todavía en los tiempos inaugurales de la República recordaba Uribe como en su primer contacto con el comité de radio de la zona minera de Vizcaya asistió a una reunión en la que el secretario, un tal Martín, apodado Petaca, «empezó preguntando a los asistentes cómo está la cuestión de las pistolas, cuántas balas tenían en depósito, si ya se habían preparado las bombas de que habían hablado. Es decir, el comité de radio se ocupaba en primer lugar, y exclusivamente en aquel caso, de hacer la revisión de los pertrechos de guerra. Este era realmente el trabajo principal del comité de radio, además de cobrar las cotizaciones».E1 extremismo conducía a casos como el de la agrupación comunista de Sestao, donde

se pasaron varios días discutiendo si aceptaban las condiciones de vida legal del Partido, es decir, las posibilidades de trabajo legal y abierto que se podía realizar durante el

1 Congreso Extraordinario del PSOE, 1921. Nacimiento del Partido Comunista Español, Madrid, ZYX, 1975, p. 3. Para este periodo, J. AvilÉs FARRE, La fe que vino de Rusia: La revolución bolchevique y los españoles (1917-1931), Madrid, UNED, 1999; y «Le origini del Partito Comunista di Spagna, 19201923). Ricerche di Storia Politica, Año 3, nº1, Enero, 2000, pp 3-28.

2 G.H. Meaker, La izquierda revolucionaria en España (1914-1923), Ariel, Barcelona, 1978, p. 571. 
régimen monárquico constitucional, porque muchos lo consideraban atentatorio a la dignidad de revolucionario aceptar y aprovecharse de las pocas libertades que concedía la monarquía. No queremos nada concedido por la burguesía, decían, se lo arrancaremos, como si lo poco logrado hasta entonces no fuese también arrancado y logrado después de decenas de años de lucha de la clase obrera y de las fuerzas democráticas españolas ${ }^{3}$.

\section{Los años de plomo (1923-1931)}

La Dictadura de Primo de Rivera 1levó al PCE a la clandestinidad. Sus fuerzas eran tan menguadas que el aparato clandestino se encubría bajo la denominación de un equipo de fútbol, el Oriente CF. La escasa proyección del partido apenas permitió ampliar su base desde los primeros tiempos. La casi totalidad de los militantes del partido, según Uribe, estaban en él desde el momento de su fundación y la organización carecía prácticamente de plataformas de expresión: La Antorcha, su primer órgano oficial, estaba suspendida, y los pocos números legales que pudieron aparecer del Joven Obrero, editado en Bilbao, fueron retirados por la policía.

Bajo la dirección de José Bullejos, Gabriel León Trilla, Manuel Adame y Etelvino Vega, el PCE se debatía entre el radicalismo, los conflictos intestinos y una deficiente praxis conspirativa. La Juventud Comunista operó durante este tiempo como el brazo ejecutor de la política más radical del partido. Las juventudes constituían el sector más dinámico de la organización, el más aguerrido y dispuesto a la lucha y el que aportaba el mayor contingente de detenidos y presos ${ }^{4}$. La mayoría de sus miembros eran obreros, aprendices y empleados que se implicaban en un estilo global de vida arriesgada y entregada a la revolución. Estaban integradas por la primera generación formada ya políticamente en el ideario comunista, sin ligaduras a la cultura socialista que aún teñía la mentalidad de los adultos que habían participado en la escisión tercerista. Por ello se convirtieron en un bastión para la bolchevización de los respectivos partidos comunistas y en una fértil cantera de futuros dirigentes. En 1927, con motivo del intento de desencadenar una huelga general en Asturias, se produjo la caída más importante del aparato comunista bajo la dictadura de Primo de Rivera ${ }^{5}$. Prácticamente toda la dirección del partido y de las juventudes fue procesada por intento de rebelión contra la seguridad del Estado, ingresando en prisión hasta la caída de Primo de Rivera.

\section{Contra la «República burguesa» (1931-1933)}

El día en que se proclamó la República, el 14 de abril de 1931, un reducido grupo de militantes -apenas un centenar- se encaminó hacia el Palacio Real para quitar la bandera monárquica y sustituirla por la roja con la hoz y el martillo, mientras proferían consignas contra la República burguesa y a favor de un gobierno obrero y campesino. Fueron recibidos

3 Archivo Histórico del Partido Comunista de España(AHPCE), Manuscritos, tesis y memorias, Memorias de Vicente Uribe, 60/6, sin paginar, Praga, 1959; para el mismo periodo, AHPCE, Manuscritos, tesis y memorias, Autobiografia de Leandro Carro, 2/7.11

4 J. Pachecho Pereira, Alvaro Cunhal. Uma biografia politica. «Daniel», ojovem revolucionario (19131941), Lisboa, Temas e Debates, 200, v. 1, p. 81-82.

5 El expediente está recogido en AHN, Fondos contemporáneos, Fondos reservados del Tribunal Supremo, Exp. 32, carpeta 8. Causa: Comunismo, 1928. Proceso por conspiración para la rebelión ... ejecutado por individuos pertenecientes al Partido Comunista Español. 
con hostilidad por la mayoría de manifestantes que aclamaban enfervorizadamente al nuevo régimen 6 . El PCE recuperó la legalidad, aunque muy menguado en sus fuerzas: en 1931 contaba con unos 4.950 miembros para todo el territorio nacional. En las elecciones a Cortes Constituyentes del 28 de junio de 1931 los comunistas recolectaron unas pocas decenas de miles de votos, insuficientes para obtener representación parlamentaria.

En 1932 tuvo lugar la caída de la cúpula dirigente del PCE y su sustitución, a instancias de la Komintern y de su delegado en España, el argentino Luis Codovilla, por el nuevo núcleo de dirección encabezado por José Díaz ${ }^{7}$. Se produjo un desembarco en el aparato de la organización de una hornada de jóvenes procedente de la Escuela Leninista de Moscú, dispuesta a la bolchevización del partido ${ }^{8}$. Se formó un nuevo equipo directivo, en el que figuraban Jesús Hernández, Vicente Uribe, Dolores Ibárruri - Pasionaria-, Pedro Checa y Antonio Mije, que sería el que dirigiera el partido durante la guerra civil.

Hasta mediados de 1934, la nueva dirección siguió aplicando las directrices de la Internacional Comunista: la confrontación con el «socialfascismo» y con el «anarquismo pequeño-burgués» en la línea de «clase contra clase» ${ }^{9}$. En diciembre de 1933 Jesús Hernández y Pasionaria participaron en las sesiones del XIII Plenario del Comité Ejecutivo de la Komintern en que se analizó la expansión del fascismo. Abundando en la retórica sectaria, los representantes españoles se preocuparon de largar una andanada contra los anarquistas, a quienes calificaban de demagogos, pustchistas, aventureros, pistoleros y abonadores del terreno para el fascismo. Lo más destacado de su aportación fue la identificación del peligro de implantación del fascismo en España con la ofensiva de los grupos monárquicos y agrarios y la autocrítica sobre la debilidad del PCE para acometer en solitario la lucha sin contar con el Partido Socialista ${ }^{10}$.

La evolución de la situación española iba a hacer cambiar muy pronto el panorama de las relaciones entre las distintas corrientes del movimiento obrero organizado. La Confederación Española de Derechas Autónomas (CEDA), de Gil Robles, y el Partido Republicano Radical (PRR) de Alejandro Lerroux obtuvieron la mayoría en las elecciones de noviembre de 1933. La izquierda, que se presentó a ellas dividida, cosechó una rotunda derrota. Los comunistas presentaron 188 candidatos en 40 provincias. Aunque no superaron el $1,2 \%$ de los votos totales emitidos, consiguieron su primer diputado de los 474 que componían la cámara al ser elegido el doctor Cayetano Bolívar, candidato por Málaga, en segunda vuelta ${ }^{11}$.

Aunque la CEDA no se integró de momento en el nuevo gobierno, el fortalecimiento de un partido católico que apenas ocultaba su reticencia hacia el sistema republicano y su admiración por el corporativismo antiparlamentario encendió las alarmas de la izquierda,

6 Bullejos, La Comintern en España. Recuerdos de mi vida, México D.F., Impresiones Modernas, 1972, p. 123 .

7 El proceso de sustitución de la dirección está analizado en A. Elorza y M. Bizcarrondo, Queridos camaradas. La internacional comunista y España (1919-1939), Barcelona, Planeta, 1999, p. 161-169.

$8 \quad$ Ibid., .p. 483.

9 La prensa comunista tronaba con este tipo de polémicas: «En este cincuentenario de la muerte del maestro, opongámonos a las traiciones de los jefes socialfascistas al grito de ¡Marx nos pertenece!», Mundo Obrero-Mundo Obrero-, 14 de marzo de 1933. "¿Contra quien luchan los jefes anarquistas?», Mundo Obrero, 17 de febrero de 1933; y «Reunión de la Mesa de la IOS: La forja de la mentira y de la capitulación' (Mundo Obrero, 3 de abril de 1933).

10 E. Comín Colomer, Historia del Partido Comunista de España, tomo II, Madrid, Editora Nacional, 1967, p. 632.

11 E. Barranquero, "Orígenes y carácter del Frente Popular», en Politicas de alianza y estrategias unitarias en la historia del PCE, Papeles de la FIM, $n^{\circ} 24,2^{a}$ época, 2006, p.35-40. 
que temía una reedición del proceso alemán. Largo Caballero juzgó llegada la hora de prepararse para pasar a la ofensiva en el caso de que se produjera la entrada de la CEDA en el gabinete. A tal fin, impulsó las Alianzas Obreras, con el fin de agrupar a las fuerzas politicas y sindicales de izquierda con el objetivo de preparar la huelga general revolucionaria cuando la ocasión se presentase ${ }^{12}$.

Desde la Komintern también se emitían señales de alerta. E1 14 de enero de 1934 las antenas de los servicios secretos británicos descifraron un mensaje emitido desde Moscú ${ }^{13}$, en el que se instaba al PCE a iniciar de inmediato una campaña para la creación en todas las fábricas y poblaciones de comités de Frente Único contra la reacción y el peligro fascista. Al mismo tiempo, debía dirigirse a las direcciones locales de PSOE, UGT, CNT, sindicatos autónomos y, en general, a todos los trabajadores a fin de organizar manifestaciones reivindicando la reapertura de los sindicatos clausurados, la libertad para la prensa obrera, el desarme y disolución de las bandas fascistas, la derogación de la Ley de Orden Público, la disolución de los jesuitas y la confiscación de todos sus bienes ${ }^{14}$. Pocos días después, por la misma vía, llegaron directrices para apoyar con toda la intensidad posible la campaña del Socorro Rojo Internacional contra la extensión del terror y el peligro de guerra ${ }^{15}$. Los acontecimientos de Austria, con el brutal aplastamiento de la municipalidad socialista de Viena por las fuerzas del gobierno de Dollfus entre el 12 y el 16 de febrero, alarmaron aún más a la izquierda. Moscú giró orden a los partidos comunistas de que organizaran demostraciones de masas en solidaridad con los obreros vieneses, campañas de prensa contra el fascismo austríaco y por el acogimiento de huérfanos de la represión ${ }^{16}$.

La primera mitad de 1934 se desarrolló en medio de grandes luchas en las que se mezclaban la acción reivindicativa de los trabajadores, el movimiento campesino y el nacionalismo democrático. Comenzó con la huelga del 19 de febrero convocada en solidaridad con los obreros austríacos, y continuó con el paro del 17 de abril contra el terrorismo fascista, la movilización contra la concentración de la CEDA en El Escorial, la gran huelga campesina del verano y la de más de 200.000 obreros de Madrid, movilizaciones a las que se sumaron los labradores catalanes el 8 de septiembre en protesta por la anulación de la Ley de Contrato y Cultivo aprobada por el parlamento autónomo. Se convocaron grandes mítines unitarios de las juventudes socialistas y comunistas y manifestaciones de repudio a los asesinatos, a manos de pistoleros falangistas, de la joven socialista Juanita Rico y del comunista Joaquín de Grado; también tuvo lugar la primera gran movilización de mujeres contra la movilización de reservistas y las acciones contra la concentración derechista de Covadonga ${ }^{17}$.

Los llamamientos a unidad de acción, sin embargo, apenas se tradujeron en resultados. Todavía el 2 de agosto Mundo Obrero explicaba la negativa comunista a ingresar en las Alianzas Obreras por considerarlas órganos estériles si no se planteaban seriamente el

12 S. JULIÁ, «Preparados para cuando la ocasión se presente": Los socialistas y la revolución», en Violencia politica en la España del siglo XX, Taurus, Madrid, 2000, p. 145-148.

13 Los servicios de inteligencia británicos lograron descifrar los mensajes transmitidos por cable entre Moscú y Madrid, al menos hasta septiembre de 1936. Se encuentran en The National Archive (TNA), en los fondos HW 17/26 y HW 17/27. El cotejo con algunos de los textos encontrados por Elorza y Bizcarrondo en los archivos exsoviéticos (RGASPI) demuestra que son los mismos que emitía y recibía la Comintern.

14 TNA, HW 17/26, 1692/Sp, 14 enero 1934.

15 TNA, HW 17/26, 1693/Sp, 29 enero 1934.

16 TNA, HW 17/26, 169y y $1698 / \mathrm{Sp}, 14$ y 28 febrero 1934.

17 J. Duclos, Mémoires. Aux jours ensoleillés du front populaire, 1935-1939, París, Fayard, 1969, t. II, p. 99-100. 
asalto al Poder. Para los comunistas, las Alianzas debían ser la trasposición de los soviets al contexto español, los órganos de un poder de nuevo tipo, el del gobierno de los obreros, campesinos y soldados ${ }^{18}$. Los días 6 y 9 se denunciaba la contradicción entre el uso de un lenguaje radical y la parálisis conspirativa por parte de los líderes socialistas:

El objetivo de toda revolución es la toma del Poder. Pues bien, llegar a ese fin es 10 preciso. No decir a grandes voces queremos esto, sino marchar a tomarlo, diciendo cómo y de qué manera. Hasta hoy sólo voces y encendidas promesas han hecho los jefes socialistas, y a cada zarpazo de la reacción, recrudecen las amenazas. Amagan, pero no dan. Y no solamente no dan, sino que impiden que se dé, so pretexto de que «se gastan energías» ${ }^{19}$.

Sin embargo, el 14 de septiembre, dando un giro a sus anteriores posiciones, el pleno del Comité Central de los comunistas tendió puentes hacia la CNT y el PSOE, aprobando el ingreso del PCE en las Alianzas Obreras. José Díaz, lo justificó afirmando: «Cuando los bolcheviques estaban en minoría en los soviets, supieron conquistar la mayoría. Es lo que haremos en las Alianzas Obreras» ${ }^{20}$.

E1 15 de septiembre, en una concentración de las milicias juveniles socialistas y comunistas, Jesús Hernández defendió por primera vez la unidad de las fuerzas marxistas en una sola central sindical y en un partido único del proletariado:

\begin{abstract}
Ahora que vemos al Partido y a la Juventud Socialista que se orientan por el camino de la Revolución, después de comprender sus errores pasados, nuestro Comité Central ha planteado la cuestión de que el Ejército de la revolución necesita una sola dirección, que el proletariado necesita un solo partido dirigente, que hay que caminar, ir con noble intención y decidido propósito a dar a la clase obrera un solo mando, un solo partido ${ }^{21}$.
\end{abstract}

Poco menos de una semana antes, el PCE había recibido de Moscú el placet para dirigir una carta abierta a la organización de las JJSS proponiéndoles la unificación sobre las bases de la Internacional Juvenil Comunista (IJC) o, en última instancia, en el Frente Único en la lucha contra la reacción y por las reivindicaciones de la juventud, plataforma de la que quedarían incondicionalmente excluidos los seguidores del trotskismo ${ }^{22}$. La invitación contenía elementos que combinaban lo viejo y lo nuevo: la pulsión por conseguir la unidad con los socialistas aún sin contar con el acuerdo de su dirección, propio de la línea del frente único por la base, con la novedosa posibilidad de renunciar a condiciones hasta entonces inexcusables -la ruptura inmediata con la organización ligada a la Internacional Obrera y la adhesión a la correspondiente de la Komintern-con tal de avanzar en el proceso unitario. Se abría por primera vez la posibilidad de llegar a una entente con el hasta entonces rival «socialfascista», y para ello era vital alejarlo primero de toda veleidad con el considerado por los comunistas principal enemigo dentro del campo proletario, el trotskismo ${ }^{23}$.

El 18 de septiembre, se advirtió al PCE de la tarea perentoria de dirigir un manifiesto a las organizaciones y trabajadores explicando la gravedad del momento y llamando a la formación de Alianzas Obreras en todas las fábricas y localidades. Esta sería la auténtica

18 «Una interviú de La Libertad. El camarada Jesús Hernández expone, en nombre del CC, su criterio sobre el frente único», Mundo Obrero, 2 de agosto de 1934.

19 «De las batallas parciales a las jornadas decisivas», Mundo Obrero, 6 y 9 de agosto de 1934.

20 «Discurso del camarada Jesús Hernández. Cordial llamamiento a los camaradas de la CNT», Mundo Obrero, 14 de septiembre de 1934.

21 «Un discurso, pleno de doctrina revolucionaria y de afirmación comunista en la lucha por el frente único, pronunciado por el camarada Jesús Hernández», Mundo Obrero, 15 de septiembre de 1934.

22 TNA, HW 17/26, 1757/Sp, 8 septiembre 1934.

23 TNA, HW 17/261762/Sp. 29 septiembre 1934. 
preparación para la conquista del poder. Su programa consistiría, entre otros objetivos, en la expropiación de los latifundistas y de la Iglesia, en el desarme de las fuerzas contrarrevolucionarias y en el armamento de los trabajadores y los eampesinos ${ }^{24}$. En vísperas de los hechos de octubre se intentaron procesos de acercamiento a Largo Caballero, al que se requirió para mantener encuentros con representantes del Comité Central o de la Komintern, si no en Moscú, en cualquier otro lugar del extranjero que él determinara ${ }^{25}$.

El anuncio de la entrada de la CEDA en el Gobierno, la noche del 3 de octubre de 1934, desencadenó el movimiento de respuesta de la Alianza Obrera. Durante las agitadas jornadas de octubre apenas hay disponible constancia de los mensajes cruzados entre Madrid y Moscú, pero es muy revelador que desde el corazón de la Komintern las directrices emanadas para su sección española planteasen medidas tan radicales como «extender la huelga general y la lucha armada de los trabajadores» junto a la aproximación con los republicanos burgueses, es decir Azaña y Esquerra Republicana de Cataluña (ERC), con el objetivo de derrocar al gobierno Lerroux, la inmediata disolución de las Cortes, la convocatoria de nuevas elecciones y la celebración de un referéndum para la confiscación de la tierra de los latifundistas ${ }^{26}$. Se mezclaban, de esta forma, una táctica que no dudaba en recurrir a métodos insurreccionales en pos de una estrategia cuyos objetivos se planteaban en términos de consolidación de una nueva mayoría parlamentaria y en reformas sociales plebiscitadas. A medida que avanzaron los días y se evidenció la derrota de las organizaciones obreras, el secretariado de la Internacional Comunista apenas pudo hacer nada más que repetir los consabidos llamamientos a la solidaridad para organizar mítines y manifestaciones en defensa de los obreros y campesinos españoles, al tiempo que dirigía un llamamiento a la Segunda Internacional en idéntico sentido ${ }^{27}$.

Como es conocido, el resultado fue una derrota sin paliativos para la izquierda que, salvo en Asturias -donde se llegaron a crear órganos de poder revolucionario- mostró imprevisión en el planeamiento, vacilación en la ejecución e incapacidad para arrastrar al movimiento a la mayor parte de la clase trabajadora organizada ${ }^{28}$. Una buena parte de la cúpula dirigente de los sindicatos, y de los partidos de la izquierda, ingresó en prisión, y su prensa fue clausurada. En la confusión de la derrota, se llegó a especular erróneamente con la muerte de Pasionaria mientras cubría supuestamente la retirada de los revolucionarios de Oviedo ${ }^{29}$.

Octubre del 34 trajo consigo consecuencias que trascendieron al fracaso y a la represión subsiguiente. Uribe se entrevistó en la cárcel con Largo Caballero, por intermediación de Álvarez del Vayo, para plantearle, entre otros asuntos, la oportunidad de que convirtiera las sesiones de su proceso en un acta de acusación contra el tribunal y el gobierno, al estilo de lo que había hecho Dimitrov en Leipzig. El líder socialista, amparándose en un sometimiento a la voluntad de su organización, persistió en negar toda participación personal y toda responsabilidad en el movimiento. Uribe piafaba ante esta respuesta:

24 TNA, HW 17/26, 1758/Sp, 18 septiembre 1934.

25 TNA, HW 17/26, 1759 y $1761 / \mathrm{Sp}, 22$ septiembre y 2 octubre 1934.

26 TNA, HW 17/26, 1763/Sp., 7 octubre 1934.

27 TNA, HW 17/26, 1765/Sp., 10 octubre 1934.

28 S. JuliÁ, «Preparados para cuando la ocasión se presente...», p. 184. Un testimonio de primera mano sobre los hechos de octubre sigue siendo la obra clásica de Amaro DEL Rosal, 1934: El movimiento revolucionario de Octubre, Madrid, Akal, 1984.

29 TNA, HW 17/26,1770/Sp., 27 octubre 1934 
Con esto se llegaba a la peregrina situación de que el máximo responsable del movimiento aparecía ente las masas como una inocente paloma que no conocía nada ni se había enterado de nada. Muchos obreros fueron a la huelga impulsados por Largo Caballero; en ella dejaron la vida unos y perdieron la libertad otros, pero a la hora de asumir la responsabilidad la rehusaron poco elegantemente.

Con menos que perder, el PCE reivindicó abiertamente la responsabilidad del movimiento insurreccional, ganando el terreno que le dejó expedito la retracción de los dirigentes socialistas. A pesar de la represión policial y de la posibilidad de incurrir en al última pena para sus máximos dirigentes, los comunistas desarrollaron una amplia campaña de propaganda en el interior y en el extranjero ${ }^{30}$. Al mismo tiempo, las enseñanzas del episodio, junto a las extraídas de otros recientes acontecimientos europeos -la amenaza de las Ligas de extrema derecha en Francia-, abrieron el camino a la formulación de una nueva estrategia unitaria, materializada en el abandono de la línea sectaria, en el acercamiento de sindicatos y partidos obreros y en la postulación de los Frentes Populares Antifascistas ${ }^{31}$.

\section{El giro hacia el Frente Popular}

En agosto de 1935, se celebró en Moscú el VII Congreso de la Internacional Comunista. Jesús Hernández, que figuraba como segundo responsable oficial de la delegación española tras José Díaz., aportó la visión española del frentepopulismo a la luz de las enseñanzas de los acontecimientos de octubre de $1934^{32}$. Comenzó haciéndose eco del informe presentado por Dimitrov, que consideró plenamente ajustado a la situación planteada por las experiencias francesa - el intento de asalto a la Asamblea Nacional de las Ligas Fascistas y de Excombatientes- y española del año anterior ${ }^{33}$. Pasó después a analizar los hechos de Asturias como la expresión de la línea de conformación del frente único y la superación histórica, por parte del movimiento obrero español, de los clásicos e ineficaces métodos insurreccionales del anarquismo. Todo ello era considerado por los dirigentes españoles como un mérito exclusivo de su partido y de la política de frente único. Tras la derrota de Octubre el PCE lanzó un llamamiento a la unidad y al agrupamiento de fuerzas al Partido Socialista y a los sindicatos obreros, al tiempo que formuló la creación de un frente popular antifascista que abarcara desde los sectores del republicanismo de izquierda, a gran parte de la intelectualidad antifascista. Todo ello unido al impulso de los Comités contra la guerra y el fascismo, en los cuales se enrolaron gran número de mujeres, y de los Comités proamnistía de los represaliados y presos de Asturias.

A comienzos de 1936, Mundo Obrero pudo aparecer de nuevo. La dirección comunista entró en un estado de agitación febril preparando las elecciones. La formulación de una amplia coalición para la recuperación de la República por parte de Azaña y los socialistas de Prieto y la aproximación táctica de un Caballero sumido en la lucha por el control

30 TNA, HW 17/26, 3428/Sp., 9 enero 1935.

31 TNA, HW 17/26, 1774/Sp., 12 noviembre 1934 y TNA, HW 17/26, 1773/Sp., 9 noviembre 1934: «E1 12 de noviembre tendrá lugar una manifestación por el Frente Unido en París, en conexión con el mitin de la Segunda Internacional. Enviad [...] uno de vuestros representantesy.

32 Citado en E. Comín Colomer, op. cit., p. 514 y siguientes.

33 Sobre el contexto internacional que coadyuvó a la formulación de la política unitaria de la izquierda, $\mathrm{P}$. GABRIEL, "Contexto internacional y Frente Popular», en Politicas de alianza y estrategias unitarias en la historia del PCE, Papeles de la FIM, Madrid, n² 24, $2^{a}$ época, 2006, p. 19-30. 
del socialismo ${ }^{34}$, en plena batalla interna contra sus adversarios, marcaría el proceso de génesis del Frente Popular. El 19 de diciembre, el partido español comunicó a Moscú la aceptación crítica de un bloque electoral de izquierdas, pero declarando su disposición a «luchar junto con la izquierda por un frente unido proletario, por las alianzas obreras» ${ }^{35}$. Dos días después, Codovilla refirió a Manuilski una entrevista con Largo Caballero para acordar posiciones. Codovilla llegó a la conclusión de que, aún estando de acuerdo con la propuesta unitaria, Caballero - que acababa de cesar en sus cargos en el partido- y los socialistas de izquierda, inmersos en las disputas internas con los centristas de Prieto, minusvaloraban el asunto central. Por su parte, la organización del PSOE había invitado ya a dos delegados del PC para decidir sobre el frente popular y las próximas elecciones ${ }^{36}$. Durante las semanas previas a los comicios conocemos principalmente las comunicaciones que Codovilla remitió a Moscú. De ellos se deducen tanto los meandros del proceso de conformación de programa y candidaturas como las maniobras de Caballero para utilizar el Fronte Popular en apoyo de su lucha partidaria: «Caballero habló en un mitin y enfatizó la necesidad de unificar las organizaciones sindicales y políticas del proletariado. Su discurso, a pesar de que suele ser bastante oscuro, favorece la presente política del PC $\rangle^{37}$.

Las negociaciones del pacto del Frente Popular no resultaron fáciles. Los republicanos no querían que los comunistas participaran en las discusiones y Largo Caballero no hizo ninguna fuerza para que las deliberaciones se efectuasen entre todos los representantes de las fuerzas políticas participantes. Según Uribe, «asomaba ya la oreja de su singular concepción del PC; nos consideraba únicamente como una fuerza de apoyo para el PSOE y especialmente para él, para sus planes». Entre las propuestas programáticas que propuso el PCE figuraban que el gobierno disolviera los partidos con formaciones paramilitares y la expropiación sin indemnización de las tierras de los grandes terratenientes y su entrega gratuita a los obreros agrícolas y campesinos trabajadores. El manifiesto contenía cuestiones que iban más allá del programa electoral, como el rápido establecimiento de relaciones con la URSS. Para Codovilla, la impresión general era buena y se estaba trabajando ya en la cuestión de los candidatos $^{38}$.

Los negociadores socialistas, encabezados por Vidarte, plantearon el tema de la incorporación de candidatos comunistas en las listas comunes en términos de que éstos alcanzaran un número de diputados «no menor que el necesario para tener derecho a constituir minoría y participar en las comisiones, es decir diez. Con esto, ellos los socialistas, tendrían un apoyo en las comisiones que es donde se elaboraban los proyectos». Hubo tira y afloja en algunas circunscripciones, como Toledo, Alicante y Sevilla, donde a pesar de los esfuerzos del PCE no se pudo incluir a ninguno de sus candidatos. Para Toledo, donde se descontaba un triunfo claro del Frente Popular, los comunistas proponían a Pedro Martínez Cartón. A éste le sentó muy mal no verse incluido por dicha provincia, y se le acabó incluyendo, aunque de mala gana por su parte, en la lista de Badajoz, en el lugar de un trotskista de Llerena -donde el POUM poseía una importante organización local-al que había propuesto como candidato Vidarte, y que había sido enérgicamente rechazado por el

34 TNA, HW-26, 5995/Sp., 30 noviembre 1935. «Caballero ha sido absuelto y nos ha informado de que va a cumplir su promesa»).

35 TNA, HW-26, 5994/Sp. 19 diciembre 1935.

36 TNA, HW-26, 5985/Sp. 21 diciembre 1935.

37 TNA, HW-26, 5891/Sp, 15 enero 1936.

38 TNA, HW-26, 5901/Sp., 16 enero 1936. 
$\mathrm{PCE}^{39}$. Paradójicamente, Cartón salió elegido diputado por la provincia extremeña, lo que no habría ocurrido en el caso de porfiar por figurar en Toledo. En Alicante, la retirada por el propio PC de la candidatura de Francisco Galán -en compensación por la retirada del PSOE a favor de candidatos republicanos- fue muy mal comprendida por la bases.

Si bien Uribe atribuyó, de forma despectiva, al «cretinismo parlamentario» de los socialistas estas discusiones, no es menos cierto qu'en las filas del propio PCE la posibilidad, por primera vez en su historia, de alcanzar grupo parlamentario suscitó movimientos de rivalidad interna en Madrid, Vizcaya o Pontevedra. A menos de quince días de la celebración de los comicios Madrid informó a Moscú que habían logrado colocarse 21 candidatos del partido, de los que se esperaba que al menos la mitad fueran elegidos ${ }^{40}$. También refirió que la intensificación de la campaña y el entusiasmo desatado estaban llevando a un incremento considerable del número de miembros del partido ${ }^{41}$. No contenía datos, pero algo más un mes después, en un Pleno del Comité Central con delegados de 47 provincias se informó que el partido contaba con 50.348 miembros y estaba en rápido crecimiento. La mayoría de los nuevos miembros procedían de las regiones agrícolas, y más de la tercera parte eran mujeres. La Juventud Comunista tenía en ese momento 32.600 miembros $^{42}$.

E1 16 de febrero de 1936, los comunistas recogieron el 3,5\% de los votos y obtuvieron 17 diputados $^{43}$. La suma de las nuevas expectativas que se abrían para las clases populares y del temor suscitado entre los sectores conservadores bosquejó el cuadro de tensión creciente que se completaría en los meses siguientes. Desde febrero, a la grave situación económica que afectaba al bajo nivel de vida de la clase trabajadora había que sumar la crisis artificial creada tras el triunfo del Frente Popular. Previendo la aplicación de la reforma agraria y las expropiaciones sin indemnización, los grandes terratenientes habían decidido abandonar las faenas agrícolas para la siguiente temporada. Se detectaban fugas de capitales, retirada de fondos bancarios, torpedeo contra el valor de la peseta, y en el aire planeaba la amenaza de un cierre patronal si el gobierno obligaba a las empresas a pagar las indemnizaciones a los represaliados de octubre del 34 .

La constitución del nuevo gobierno Azaña fue objeto de valoraciones confusas por parte de la Komintern. Si en primera instancia se consideró no como un gobierno de Frente Popular, sino como un gobierno burgués de izquierda ${ }^{44}$, sin embargo Moseú consideró que debía ser apoyado contra los ataques y el posible golpe de estado de los reaccionarios para garantizar que pudiera llevar a cabo el programa electoral del Frente Popular, sin perjuicio de que el PCE mantuviese una acción independiente y se reservase el derecho a la crítica

39 Codovilla llegó a transmitir a Manuilski que esto obedecía a alguna maniobra oculta del aparato socialista controlado por Prieto: «El comité ejecutivo del PS ha maniobrado para remover candidatos de la izquierda socialista y comunistas, usando a los candidatos trotskistas en las provincias con intención de forzar a nuestro partido a romper con el bloque. Nuestro partido ha [¿denunciado?] la maniobra pero no ha roto. TNA. HW-26, 5232/Sp. 4 febrero 1936.

40 TNA. H.W, 26. 5232/Sp. 4 febrero 1936.

41 TNA, HW-26, 5232/Sp., 4 febrero 1936.

42 TNA, HW-26 5631/Sp., 31 marzo 1936.

43 Archivo del Congreso de los Diputados (ACD), Documentación electoral, 141, n 16.

44 TNA, HW-26, 5300/Sp., 26 febrero 1936. La argumentación se basaba en que: «1. Las organizaciones de los trabajadores no están representadas en este gobierno, solo el partido republicano (sic). 2. Este gobierno no ha entregado tierra de los propietarios, el estado y la iglesia a los campesinos. 3 . Necesariamente vacilará». 
y a la movilización cuando los métodos del Gobierno fueran dirigidos contra los intereses de las clases trabajadoras ${ }^{45}$.

Las semanas siguientes transcurrieron agitadas, bajo el triple signo de la presión popular para que el gobierno llevase a cabo reformas profundas, con verosímiles amenazas de desbordamiento ${ }^{46}$; de la lucha interna en el PSOE, en la que la facción caballerista parecía abonarse a ese radicalismo que podía terminar con la ruptura del bloque popular; y de los movimientos para llevar a cabo la consecución de la unidad orgánica del proletariado, empezando por la fusión de las juventudes.

El PCE, según informó Codovilla a Dimitrov, apostaba por el programa de la revolución democrático-burguesa (al que atribuyó, de forma sin duda exagerada, un aplastante apoyo de masas ${ }^{47}$. Los comunistas apoyaban las ocupaciones de tierra de forma organizada, como forma de obligar al IRA a acelerar sus pasos, pero limitándose «sólo [a] ocupar la tierra de la exnobleza, de los terratenientes reaccionarios importantes, de la Iglesia, tierras excomunales, etc. Lo mismo con los almacenes de grano». El partido hacía todos los esfuerzos «para consolidar las posiciones conquistadas y para apoyar, pero no precipitar luchas prematuras».

En aquel contexto resultaba suicida creer, como lo hacían los socialistas de izquierda, que el bloque popular había cumplido su misión y había que disolverlo. De cara a las elecciones municipales los comunistas propusieron a Caballero acordar un programa común que contuviera las reivindicaciones esenciales de la revolución democrático-burguesa, reforzar la unidad proletaria organizando conjuntamente las alianzas obreras y campesinas y discutir sobre la formación del partido único. Sobre este último aspecto se dieron pasos decisivos a últimos de marzo. En concreto, en su reunión del último día del mes el Comité Central aprobó unánimemente las razones adoptadas para la fusión de las juventudes comunista -que decía contra con 35.246 miembros $^{48}$ - y socialista. Es interesante señalar que ya en esta reunión del órgano de dirección comunista tomó parte Santiago Carrillo, que «hizo una magnifica sugerencia política, declarar que la IS se propone adherirse definitivamente a la KIM [Internacional Juvenil Comunista] y procurar que el PS reformado junto con el PC se adhiera a la $\mathrm{IC} \gg^{49}$.

En el rampante clima de tensión a que estaba conduciendo la actuación de los pistoleros falangistas convenía no caer en provocaciones y evitar responder al atentado con el atentado. A ello se sumaba, además, la preocupación de la Komintern, expresada por boca de Dimitrov y Mauilski, por la actuación, calificada como «contrarrevolucionaria», de dos vectores: los socialistas de izquierda - junto con los inevitables «trotskistas»-, con sus intentos de destruir el frente popular; y los anarquistas, de los que se temía un putsch. La

45 Para no dejar lugar a dudas, en la misma fecha que se dio la directriz anterior se remitió un segundo cable que suprimía las consideraciones negativas sobre el gobierno: «Cancelad [el anterior mensaje]. Sustituidlo por este que sigue a continuación (Suprime la primera mitad, donde figuran los tres puntos numerados)». TNA, HW-26, 5308/Sp., 26 febrero 1936.

46 La situación política es la siguiente: «El gobierno Azaña, bajo la presión política de las masas, está llevando a cabo el programa del bloque popular, y va más allá [...] La situación revolucionaria se desarrolla rápidamente. La solución del problema de la tierra por métodos revolucionarios, no pasará mucho tiempo en plantearse con el desarrollo de la lucha, así como el problema del poder». TNA. HW26, 5382/Sp., 4 marzo 1936.

47 «En la manifestación del 1 de marzo en Madrid, en la que tomaron parte más de 500.000 personas, nuestros slogans sobre la revolución democrático-burguesa fueron aclamados por una inmensa mayoría de los manifestantes». TNA. HW-26, 5382/Sp., 4 marzo 1936.

48 TNA. HW-26,5316/Sp., 4 abril 1936

49 TNA. HW-26, 5631/Sp., 31 marzo 1936. 
colusión de ambas fuerzas no podría dejar de tener fatales consecuencias para la unidad del Frente Popular en el parlamento.

La Internacional Comunista realizó un llamamiento dramático a su seceión española para que no cayera en ninguna provocación, ya que «sería perjudicial a la revolución en este momento y podría sólo favorecer el triunfo de loa antirrevolucionarios». Había que impedir que se produjera una ruptura con los republicanos burgueses de Azaña, ni siquiera darles el pretexto para que se apoyasen en elementos reaccionarios. Se debían emplear todos los medios para acelerar la realización del programa del Frente Popular, particularmente la cuestión agraria. La directriz terminaba haciendo hincapié en la necesidad de apartar el espantajo del peligro rojo: «En todas las actividades del partido que realicéis se debe resaltar que la creación del poder soviético no está en el orden del día, sino que por el momento, es solamente cuestión de establecer un estado democrático que haga posible ejercer una barrera contra el avance del fascismo y la contrarrevolución, y para fortalecer en general las posiciones del proletariado y sus aliados» ${ }^{50}$.

Por más que se apelase a la contención, la tensión siguió aumentando. El 14 de abril, se produjeron incidentes en el Paseo de la Castellana, durante los cuales unos falangistas dispararon contra la presidencia del desfile conmemorativo de la fiesta nacional, resultando muerto durante los enfrentamientos un alférez de la Guardia Civil ${ }^{51}$. Su entierro derivó en nuevos tiroteos entre los participantes en el cortejo-simpatizantes de la extrema derecha-y miembros de las milicias socialistas que los hostilizaban en su marcha hacia el cementerio del Este ${ }^{52}$, con un balance de tres víctimas mortales más. Se desencadenó una huelga general en Madrid, de la que Codovilla dio cuenta a Manuilski. El PCE habría hecho todo lo posible por evitarla y, aunque no se atreviera a manifestar en público su disconformidad con el paro, iba a instar el retorno al trabajo en pos de evitar que las masas fuesen arrastradas a ellos por los anarquistas, que pretendian convertir la huelga general en indefinida ${ }^{53}$. La actitud comunista de firme de apoyo al Gobierno se reiteró en el mensaje en que se daba cuenta del final del paro dos días más tarde. El PCE se atribuyó, junto con la mayor parte de los socialistas, el mérito del rumbo impreso a la movilización, de protesta contra las aetividades de los grupos fascistas y apoyo a las fuerzas de policía. No significaba ello que no hubiese habido en el seno del propio partido contradicciones e incomprensiones hacia una línea tan moderada. «En algunos casos, -se informaba- la presión de los socialistas de izquierda y los anarquistas se ha hecho sentir en nuestras filas, y para no parecer menos revolucionarios, se han hecho algunas concesiones». Fue necesario, para ajustar el rumbo, discutir las directrices de la IC en el BP con el objeto de confirmar definitivamente la línea táctica del partido en este momento, y lograr que todos los miembros la entendieran ${ }^{54}$.

La dirección comunista española estaba preocupada por la táctica adoptada por la izquierda socialista, consistente, a su juicio, en incitar a las masas «contra el odiado sector militar y por lo tanto llevar a cabo la revolución proletaria inmediatamente». Como muestra, una parte de los incidentes durante el desfile del 14 de abril tuvieron lugar cuando, al paso de unidades de la Guardia Civil, sectores del público, con los puños en alto, prorrumpieron

50 TNA, HW-26, 5810/Sp., 9 abril 1936

51 Los sucesos están prolijamente descritos en La Vanguardia de los días 15 al 19 de abril. También hace referencia a ellos M. TAGüEÑa, Testimonio de dos guerras. Barcelona, Planeta, 2005, p. 93-94)

52 La prensa señaló que algunos de los disparos efectuados desde las azoteas lo fueron por «individuos con boina y camisas rojas», La Vanguardia, 17 abril 1936.

53 TNA, HW-26, 5743/Sp., 16 abril 1936.

54 TNA, HW-265733/Sp. 18 abril 1936. 
en gritos de ¡UHP! (Unión Hermanos Proletarios), Asturias quedaba todavía muy cerca. A ello se añadía el peligro de un pustch anarquista, apoyado en la impaciencia revolucionaria de esas mismas masas. Todo ello hacía sumamente necesario el mantenimiento de una actitud de vigilancia por parte del $\mathrm{PC}^{55}$.

Mientras tanto, seguía la estrategia unitaria, dependiente en buena parte de las tensiones internas y el juego de tendencias en el PSOE. Los comunistas fijaron la fecha de su congreso el 12 de julio, unos días después del congreso socialista, para orientarse hacia la fusión de ambas organizaciones. Entre los dirigentes comunistas locales se extendía la impresión de que los socialistas de izquierda maniobraban para evitar la fusión y la adhesión a la IC, porque lo que deseaban era la entrada en masas de los comunistas en el partido socialista para incrementar su fuerza fraccional ${ }^{56}$. En este proceso emergió la obsesión por la actividad trotskista. Desde Moscú, Dimitrov alertó al PCE contra antiguos comunistas expulsados y por aquel entonces activos en el seno de otras organizaciones de izquierda: en concreto, aludió a las posibles maniobras de Bullejos en la Juventud Socialista y a la creciente actividad de Maurín en Cataluña. Este último era, con mucho, el más peligroso. El partido y su prensa no estaban haciendo prácticamente ninguna campaña contra el trotskismo. Era imperativo concentrar todas las baterías sobre él, empleando la denuncia pública para «desenmascarar la política aventurera de Maurín y $\mathrm{C}^{\mathrm{ia}}$, sus relaciones con Doriot ${ }^{57}$, un agente de Hitler, sus actividades escisionistas, [y] su hostilidad al frente popular». La unificación de las fuerzas proletarias de Cataluña adquiría una finalidad específica: arranear a las masas de la influencia de Maurín. En esta tarea resultaba prioritario educar a los nuevos miembros del partido en el papel contrarrevolucionario de los trotskistas en la URSS, España y otros países ${ }^{58}$.

La lucha entre facciones socialistas estaba poniendo en riesgo la unidad del Frente Popular y la estabilidad del Gobierno. Con la elevación de Azaña a la presidencia de la República, tras la destitución de Alcalá Zamora, Caballero y la UGT declararon su voluntad de separarse del Frente Popular. En vista de la gravedad de la situación, Codovilla mantuvo una entrevista con Caballero, a quien después de alguna discusión, logró convencer de que la ruptura sería un grave error y le comprometió a no sólo no romper el Frente Popular, sino fortalecerlo, y a preservar el frente unido de los partidos obreros y la UGT ${ }^{59}$.

La tensión no daba tregua. En unos casos se trataba de la reedición de viejos episodios de violencia entre campesinos y fuerza pública. El 29 de mayo de 1936, en Yeste (Albacete) se produjo un enfrentamiento de esta naturaleza que culminó con un balance de 18 muertos (17 vecinos y un guardia civil), más de 17 heridos y un gran número de detenidos ${ }^{60}$. Dimitrov hizo llegar a Díaz un cable en el que manifestaba conceder «extraordinaria importancia a los hechos que han ocurrido en la provineia de Albacete [...] porque estas acciones perjudican al Frente Popular, comprometen al gobierno y favorecen a los contrarrevolucionarios». Recomendaba tomar las medidas necesarias para que estos acontecimientos no volvieran

55 TNA, HW-26, 5811/Sp., 26 abril 1936.

56 TNA, HW-26, 5808/Sp., 27 abril 1936.

57 Antiguo dirigente comunista francés, expulsado del partido en abril de 1934 por sus discrepancias frente a la línea, mantenida por la Komintern y por Thorez, de rechazo a la alianza con los socialistas. Experimentó un giro a la derecha que le llevó a la creación del Partido Popular Francés (PPF), de corte fascista.

58 TNA, HW-26, 5828/Sp., 29 abril 1936.

59 TNA, HW-26, 5923/Sp., 9 mayo 1936.

60 Sepúlveda R.M. Losa, «La primavera conflictiva de 1936 en Albacete», en Pasado y Memoria. Revista de Historia Contemporánea, n² (2003), edición digital: http://publicaciones.ua.es/filespubli/ pdf/15793311RD26129438.pdf 
a ocurrir y la formación de una comisión parlamentaria para investigar y descubrir a los autores «de esta criminal provocación $»^{61}$.

En otros casos, la violencia era resultado de la rivalidad entre las propias organizaciones obreras. El 10 de junio de 1936, fue asesinado de un disparo, durante una huelga convocada por el Sindicato de Pescadería de la CNT, el concejal comunista de Málaga Andrés Rodríguez, opuesto a las reivindicaciones de los huelguistas. Al día siguiente, cuando salía de su domicilio para asistir al sepelio, fue también asesinado el Presidente de la Diputación Provincial, el socialista Antonio Román Reina ${ }^{62}$. El Secretariado de la Internacioanl Comunista instaba nuevamente, para rebajar tensiones, a la apertura de una comisión de investigación y al diálogo al máximo nivel entre las dos centrales obreras para acabar con las hostilidades ${ }^{63}$.

La agudización de las tensiones sociales y políticas en España tras el triunfo del Frente Popular y la preparación del V Congreso que el PCE debería celebrar a partir del 12 de julio hizo que Moscú convocara a los dirigentes del partido al Presidium del Comité Ejecutivo de la Internacioanl Comunista, en la sesión del 22 de mayo de $1936^{64}$. En esta reunión, Hernández presentó a la Internacional el programa del próximo congreso del partido, cuyo orden del día, aparte de los aspectos sectoriales y orgánicos, tendría como eje principal la formación del Partido Único del Proletariado ${ }^{65}$. Comenzó pasando revista a la situación del país en los convulsos meses de la primavera de 1936. Las elecciones, a pesar de los condicionamientos en contra - «la derecha hizo campaña con el lema: Votar al Frente Popular es votar a Dimitrof (sic), votad por España y contra Dimitrof»- habían sido un triunfo de las masas antifascistas, gracias fundamentalmente a la política de Frente Popular que el PCE no dudaba en arrogarse como propia. A ello habían contribuído factores inéditos como la orientación hacia la izquierda del voto de las mujeres y la participación electoral de las bases anarcosindicalistas. A la clásica cuestión ¿qué hacer?, Hernández respondía que la situación obligaba al partido a plantearse el problema de la reorganización de la economía del país sobre una nueva base. En concreto, postulaba la nacionalización de algunas industrias, en primer lugar la del carbón, para después obligar a las industrias del transporte, ferrocarril, barcos, etc. a consumir carbón nacional. En el campo, cuya situación era explosiva ${ }^{66}$, proponía llevar a cabo una campaña de agitación nacional bajo el lema Es necesario salvar al pais del hambre, planteando la alternativa de expropiar las tierras que no se trabajasen para ser distribuidas entre los campesinos, con el compromiso de entrega por parte del Estado de stocks de semillas y la habilitación de créditos al consumo. Para

61 TNA, HW-26, 6098/Sp., 2 junio 1936.

62 S.J. BRenes CoBos, «Andrés Rodríguez, concejal comunista de Málaga (1931-1936)», en Revista Jabega, $\mathrm{n}^{\circ} 88$, Centro de ediciones de la Diputación de Málaga, 2001. Edición digital: http://www. cedma.com/archivo/jabega pdf/jabega88 71-81.pdf

63 «Diaz, Luís. Estamos enormemente perturbados por la feroz lucha desatada entre trabajadores de la UGT y la CNT que ha tenido lugar en Málaga y en otras provincias. Os invitamos a hablar con Caballero para que eleve una proposición en nombre de la UGT al comité nacional de CNT con el objeto de abrir una comisión parlamentaria de investigación y conciliación con el fin de liquidar las hostilidades entre los partidarios de las dos organizaciones en Málaga», TNA, HW-26, 6199/Sp., 21 junio 1936.

64 TNA, HW-26, 5834/Sp., 1 mayo 1936. «Díaz, Luís. Luís debe venir inmediatamente con información de la situación. Sería bueno que viniera con él uno de los miembros del BP, si no hay dificultad. Dios».

65 Russian State Archive of Socio-Political History (RGASP) I, f. 495, op2. d. 245, p. 124-163. Hay también una copia en francés. Agradezco la referencia de este informe a Ángel Viñas.

66 El estudio más reciente sobre la situación en el agro meridional en este momento es el de F. EsPINOSA, La primavera del Frente Popular Los campesinos de Badajoz y el origen de la guerra civil (marzo-julio de 1936), Barcelona, Crítica, 2008. 
aliviar la situación del campo y la de los obreros sin trabajo, el PCE proponía realizar un vasto plan de obras públicas, de irrigación, de electrificación, construcción de caminos e higienización de los pueblos, para lo cual era necesaria una fuerte inversión estatal, cuyos fondos procederían de un impuesto progresivo sobre la propiedad rústica y sobre la renta en general, sobre los beneficios de los bancos, las sociedades anónimas y las grandes industrias. Si ello no bastaba, sería necesario un empréstito forzoso sobre el Banco de España y los grandes capitales.

El Gobierno, en cumplimento de sus compromisos electorales, adoptó medidas para reparar a los represaliados y perseguidos durante lo que se conoció como Bienio negro: Se promulgó el decreto sobre readmisión con indemnización ( 3 a 6 meses de salario) de los despedidos de octubre, se aprobó la amnistía general, se puso en vigor de nuevo el Estatuto de autonomía catalán y se aprobó el vasco, se revisaron los desahucios de campesinos y se restableció la legislación social del primer bieno. Por otra parte, se ilegalizó a Falange y se procedió a una depuración superficial de las fuerzas represivas y del Ejército, con el nombramiento de una comisión de investigación sobre la represión

Sin embargo, en el ámbito económico y social, el Gobierno, integrado en exclusiva por republicanos burgueses, no actuaba con diligencia a no ser que se le sometiera a presión mediante huelgas económicas, políticas, de ocupados y parados, parciales y generales, con ocupación de fábricas e invasiones en masas de fincas. Era en estas circunstancias cuando el Estado se veía obligado a intervenir a través de sus delegados de trabajo, y en general su dictamen, según Hernández, era favorable a los obreros.

Respecto a la inquietud que generaban en el extranjero incidentes como el incendio de establecimientos religiosos, Hernández procuró alejar de la responsabilidad sobre ello a los comunistas. El PCE era contrario al anticlericalismo visceral, lo que no fue óbice para que diera pábulo a los extendidos rumores que hablaban de que en el interior de algunos templos se encontraban «depósitos de armas fascistas o que desde ellas se ha hecho fuego contra manifestaciones populares».

Adecuándose rápidamente a la nueva estrategia, el PCE iba ganando aceleradamente espacios de visibilidad y respetabilidad. En ese contexto, y sin olvidar que el Gobierno no era más que un gobierno republicano de izquierda, o sea, burgués, los comunistas españoles llegaron a la conclusión de que «podemos seguir un gran trecho del camino en común, para mejorar las condiciones de vida, de trabajo, de cultura y bienestar de las masas laboriosas de nuestro país y asestar golpes serios a las fuerzas de la reacción y el fascismo». El giro hacia la política de Frente Popular en la acepción canónica de Dimitrov había llegado a su conclusión. Al calor del antifascismo crecían las dinámicas unitarias entre las organizaciones marxistas de la clase trabajadora española. Tras la fusión de la comunista Confederación General del Trabajo Unitaria (CGTU) con la UGT, esta central sindical contaba con 745.000 obreros industriales, unos 253.000 campesinos y más de 200.000 obreros en trance de afiliación. La CNT, que declaraba 559.000 adherentes, también se reforzaba aunque no al ritmo impetuoso de la UGT. El gran éxito unitario lo constituía la creación de la Juventud Socialista Unificada (JSU) ${ }^{67}$. Desde el punto de vista orgánico, el resultado de la fusión iba más allá de la mera suma de efectivos, desencadenando efectos sinérgicos: si la Juventud Comunista tenía antes del 16 de febrero 14.000 miembros y en el momento de la fusión contaba con 50.680; y la JS contaba con unos 65.000, dos o tres

67 Para este proceso, ver R. VinYES, La formación de las Juventudes Socialistas Unificadas (1934-1936), Madrid, Siglo XXI, 1978. 
semanas después de la fusión la Juventud Unificada tenía ya 140.000 miembros. A ellos había que añadir decenas de miles de pioneros, entre 40 y 50.000 mujeres y unos 30.000 jóvenes en la Federación Deportiva Obrera.

Las relaciones con el Partido Socialista fueron objeto de especial atención, particularmente con el sector que seguía a Largo Caballero. Los comunistas se mostraban preocupados por el peligro de escisión que se había acentuado considerablemente en el seno del PSOE. El PCE se comprometía a impedir, en la medida de sus posibilidades, la escisión socialista y a «apoyar la labor de depuración de los elementos derechistas y de la parte más podrida del centro» liderado por Indalecio Prieto, en pos del objetivo de formar a medio plazo el partido único del proletariado.

En lo tocante a las propias fuerzas, el PCE señaló que pudo salvar a la mayoría de cuadros dirigentes tras la derrota de Octubre, a excepción de Asturias, donde el partido fue casi deshecho. Desde entonces, al calor de las campañas frentepopulistas, la recuperación había sido un hecho: antes de las elecciones de febrero el partido tenía alrededor de 20.000 miembros; en el mes de mayo tenía registrados 83.967. El PCE se estaba transformando en un partido de masas entre cuyos objetivos figuraba alcanzar los 100.000 afiliados para la fecha de la celebración del V Congres ${ }^{68}$. El reclutamiento más importante procedía de las zonas agrícolas y de las ciudades de tipo semi-industrial (Málaga, Sevilla, Jaén, Valencia, Badajoz, etc.), y de los centros mineros (Asturias y, en menor medida, Vizcaya). La mayoría de los nuevos miembros eran obreros organizados en la UGT y sólo una mínima parte no habían estado organizados con anterioridad. Era escaso el número de nuevos adherentes procedentes del PSOE, «ya que el partido no hace una campaña especial para lograr miembros del ala izquierda del PS puesto que la perspectiva es la de fusionar sus fuerzas y las nuestras» y mucho más escaso aún el de procedentes del anarquismo. Los puntos débiles del fortalecimiento de la organización eran dos: la carencia de cuadros formados para educar a la avalancha de nuevos militantes y la escasa presencia en Cataluña. En buena lógica leninista, el primer objetivo debía ser fortalecer la cadena de responsabilidad entre la cúspide y las bases «para garantizar que las instrucciones que se trasmiten a las células se cumplen». En lo tocante a Cataluña, el partido apenas sobrepasaba los 2.000 adherentes en aquel territorio a causa de la gran fragmentación de organizaciones (PCC, Partí Catalá Proletari, Unió Socialista...) y la incomprensión del problema nacional catalán -una carencia endémica entonces y después para la dirección central del comunismo español-. Por si fuera poco, había que sumar la larga tradición fraccional sufrida por el marxismo en aquel territorio, lo que pasaba factura en forma de debilidad del sector ortodoxo frente a la organización encabezada por el disidente Joaquín Maurín, el Bloque Obrero y Campesino. El primer paso hacia la lucha por la hegemonía -que tantos conflictos iba a generar en la Cataluña en guerra- se estaba comenzando a dar con la aproximación de las fuerzas simpatizantes de la Internacioanl Comunista para la formación del Partido Socialista Unificado de Cataluña (PSUC).

El análisis de Hernández sobre los peligros que se cernían a corto y medio plazo sobre el Gobierno combinaba a partes iguales preocupación, apreciaciones clamorosamente erróneas y declaraciones de profundización en la línea frentepopulista. En cuanto al problema del peso de los sectores reaccionarios en el Ejército y a su capacidad para desencadenar un

68 Los acontecimientos, tal como ocurrieron, iban a desbordar las previsiones. A raíz del levantamiento militar, los afiliados pasaron a ser 118.763; casi un año más tarde, en marzo de 1937, alcanzaba el cuarto de millón. AHPCE, Film XVI, 1937. 
levantamiento lo consideraba preocupante, si bien se dejaba llevar por lo que juzgaba «un cierto desplazamiento de la oficialidad hacia el Frente Popular como asimismo hacia nuestro partido $»^{69}$. Con respecto al futuro, consideraba que «la lucha actual está planteada entre fascismo y antifascismo, entre revolución y contrarrevolución, lucha que aún no está terminada ni decidida. El Partido se desarrolla rápidamente, pero la dirección no olvida que los éxitos logrados no están aún consolidados definitivamente. Justamente porque la lucha tiene este carácter todavía en nuestro país es por lo cual nosotros no planteamos como perspectiva inmediata la instauración del poder soviético sino la lucha por la consolidación de la República democrática, es decir, que tomamos la orientación de la terminación de la Revolución democrático burguesa, punto en el cual discrepamos de los socialistas que estiman aún en su inmensa mayoría que el problema actual es la lucha directa por la dictadura del proletariado y por el socialismo»».

Con este conjunto analítico el PCE consolidaba una trasformación fundamental. En menos de una década - si se considera en un tiempo largo- o de un lustro, mirándolo a corto plazo, el Partido Comunista había pasado de ocupar un lugar marginal, alojado en el extremo radical, violento y sin capacidad alguna de influencia del sector político de la izquierda, limitado a un puñado de activistas con una estereotipada, escasa e ineficaz percepción de la realidad, a ubicarse en un espacio de centralidad, al calor del movimiento unitario desplegado por la oposición a la extensión del fascismo en la segunda mitad de los años 30 . Todos $-o$ casi todos- los temas que agitarían la relación entre las fuerzas de la izquierda, la pugna por la hegemonía y la filosofía de la naturaleza del proceso que se abriría con la Guerra civil se encontraban ya en el arsenal estratégico del PCE antes de iniciarse el conflicto.

69 En el entierro del capitán Faraudo, instructor de milicias asesinado por falangistas, Hernández puso de manifiesto que los comunistas «no somos enemigos de los militares ni del ejército, ni queremos destruir la disciplina sino simplemente depurarlos de todos los elementos fascistas». 